\title{
BMJ Open Risk factors for postneonatal, infant, child and under-5 mortality in Nigeria: a pooled cross-sectional analysis
}

\author{
Osita Kingsley Ezeh, ${ }^{1}$ Kingsley Emwinyore Agho, ${ }^{2}$ Michael John Dibley, ${ }^{3}$ \\ John Joseph Hall, ${ }^{4}$ Andrew Nicolas Page ${ }^{2}$
}

To cite: Ezeh OK, Agho KE, Dibley MJ, et al. Risk factors for postneonatal, infant, child and under-5 mortality in Nigeria: a pooled crosssectional analysis. BMJ Open 2015;5: 006779 .

doi:10.1136/bmjopen-2014006779

- Prepublication history for this paper is available online To view these files please visit the journal online (http://dx.doi.org/10.1136/ bmjopen-2014-006779)

Received 29 September 2014 Revised 3 March 2015 Accepted 4 March 2015

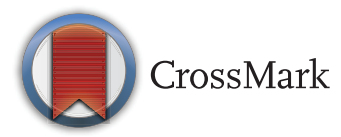

${ }^{1}$ School of Medicine, University of Western Sydney, Campbelltown, New South Wales, Australia

${ }^{2}$ School of Science and Health, University of Western Sydney, Campbelltown, New South Wales, Australia ${ }^{3}$ Sydney School of Public Health, University of Sydney, Sydney, Australia

${ }^{4}$ Faculty of Health, School of Medicine and Public Health, University of Newcastle, Callaghan, New South Wales, Australia

Correspondence to Osita Kingsley Ezeh; ezehosita@yahoo.com

\section{ABSTRACT}

Objectives: To identify common factors associated with post-neonatal, infant, child and under-5 mortality in Nigeria.

Design, setting and participants: A cross-sectional data of three Nigeria Demographic and Health Surveys (NDHS) for the years 2003, 2008 and 2013 were used. A multistage, stratified, cluster random sampling method was used to gather information on 63844 singleton live-born infants of the most recent birth of a mother within a 5 -year period before each survey was examined using cox regression models.

Main outcome measures: Postneonatal mortality (death between 1 and 11 months), infant mortality (death between birth and 11 months), child mortality (death between 12 and 59 months) and under-5 mortality (death between birth and 59 months).

Results: Multivariable analyses indicated that children born to mothers with no formal education was significantly associated with mortality across all four age ranges (adjusted $\mathrm{HR}=1.30,95 \% \mathrm{Cl} 1.01$ to 1.66 for postneonatal; $\mathrm{HR}=1.38,95 \% \mathrm{Cl} 1.11$ to 1.84 for infant; $\mathrm{HR}=2.13,95 \% \mathrm{Cl} 1.56$ to 2.89 for child; $\mathrm{HR}=1.19,95 \% \mathrm{Cl} 1.02$ to 1.41 for under-5). Other significant factors included living in rural areas ( $\mathrm{HR}=1.48,95 \% \mathrm{Cl} 1.16$ to 1.89 for postneonatal; $\mathrm{HR}=1.23,95 \% \mathrm{Cl} 1.03$ to 1.47 for infant; $\mathrm{HR}=1.52$, $95 \% \mathrm{Cl} 1.16$ to 1.99 for child; $\mathrm{HR}=1.29,95 \% \mathrm{Cl} 1.11$ to 1.50 for under-5), and poor households ( $\mathrm{HR}=2.47$, $95 \% \mathrm{Cl} 1.76$ to 3.47 for postneonatal; $\mathrm{HR}=1.40,95 \%$ $\mathrm{Cl} 1.10$ to 1.78 for infant; $\mathrm{HR}=1.72,95 \% \mathrm{Cl} 1.19$ to 2.49 for child; HR=1.43, $95 \% \mathrm{Cl} 1.17$ to 1.76 for under-5).

Conclusions: This study found that no formal education, poor households and living in rural areas increased the risk of postneonatal, infant, child and under-5 mortality among Nigerian children.

Community-based interventions for reducing under-5 deaths are needed and should target children born to mothers of low socioeconomic status.

\section{INTRODUCTION}

Globally, the mortality rate of children aged under 5 years has reduced from 90 deaths per 1000 live births in 1990 to 48 deaths in

\section{Strengths and limitations of this study}

- This study is based on nationally representative household surveys that reflect every locality in Nigeria.

- Data were pooled together to create large sample sizes of deaths reported within 5 years preceding the surveys.

- Analyses were restricted to births within 5 years of each of the surveys to reduce recall bias by mothers interviewed and to minimise bias that may have arisen from changes in household characteristics.

- Newborns' dates of birth and death given by mothers may have been misreported-particularly those that had occurred a few months or years before the survey.

- Causes of death and medical conditions of children were unknown at the time of survey.

2012; but the rate still remains very high in sub-Saharan Africa (from 177 to 98 deaths). In 2012, approximately half the world's estimated 6.6 million deaths in children aged less than 5 years occurred in sub-Saharan Africa, and Nigeria accounted for approximately $13 \%$ of these deaths. ${ }^{1}$ The majority of these deaths are caused by communicable diseases such as malaria, diarrhoea, measles, cholera and respiratory infections. While these deaths are both preventable and treatable, the lack of effective health intervention policies has resulted in a high under-5 child mortality rate (U5MR) in the region.

Childhood mortality remains a major public health challenge in Nigeria despite the substantial global decline in childhood deaths. Currently, the country has the highest reported number of under-5 deaths in Africa and ranks as having the second highest number (after India) worldwide. Nearly one million children aged under 5 years die in Nigeria annually and more than $60 \%$ of these deaths occur between 1 and 59 months of life. ${ }^{1}$ Evidence from the 
Nigeria Demographic and Health Surveys (NDHS) showed that over a 10-year period (from 2003 to 2013), infant mortality rates (IMR) fell by $31 \%$ (from 100 to 69 deaths per 1000 births); postneonatal mortality rates (PMR) dropped by approximately $40 \%$ (from 52 to 31 deaths); and child mortality rates (CMR) declined by approximately $43 \%$ (from 112 to 64 deaths). Similarly, U5MR decreased by approximately 36\% (from 201 to 128 deaths). ${ }^{2}{ }^{3}$ The current U5MR of 128 deaths per 1000 live births reported by the NDHS implies that approximately one in every eight children aged under 5 years in Nigeria dies before having a fifth birthdayapproximately 21 times the average rate for developed countries (6 deaths per 1000 live births). ${ }^{1}$ With this marginal reduction in childhood deaths, it is more likely that Nigeria will not achieve the Millennium Development Goal target of 76 deaths per 1000 live births by 2015.

Previous studies on childhood mortality in Nigeria have included multiple births in their analyses by primarily using one single data set to examine factors associated with under-5 child mortality. ${ }^{4-10}$ However, these studies have limited generalisability, in part, because of the limited number of deaths recorded in any single NDHS. Other studies have also found that including multiple births in the analysis of factors associated with under-5 child mortality may produce inaccurate mortality risk estimates compared with using only singleton births in the analysis. ${ }^{11-18}$

Inadequate health facilities, insufficient skilled health professionals and lack of modern medical equipment have undermined the Nigerian healthcare system, particularly in rural areas. ${ }^{19}$ As a result, the Nigerian Government launched and implemented a National Health Policy (NHP) and Ward Health System (WHS) whose core targets include reduction of under-5 mortality rate. ${ }^{3}$ Despite all these initiatives, deaths of children $<5$ years of age still remain high in Nigeria. Hence, this present study aimed to identify common factors that affect childhood mortality in Nigeria in different age ranges of the first 59 months of life (infant, 0-11 months; postneonatal, 1-11 months; child, 12-59 months; and under-5, 0-59 months). Using pooled data may provide an important framework for public health researchers and policymakers in reviewing and designing new child survival intervention strategies. ${ }^{20}$

\section{METHODS}

The data sets used in this study were the 2003, 2008 and 2013 NDHS surveys, pooled together to maximise the sample sizes of deaths. Information on births and deaths of children aged younger than 5 years was obtained from 79953 eligible women, aged 15-49 years, who participated in the surveys. ${ }^{23} 21$

From these women, data on a (weighted) total of 66154 live-born infants were obtained, including singleton and multiple births of the mothers' most recent birth within 5 years prior to the survey date. The number of live births included was 6219 from the 2003 survey; 28107 from the 2008 survey and 31828 from the 2013 survey. A total of 2310 multiple births were excluded in the final analyses. The analyses were restricted to live births and most recent births during the 5 years preceding the surveys to limit mothers' potential for differential recall of events, as deliveries had occurred at different points in time prior to the interview. Detailed sampling methods used in gathering the data have been reported elsewhere. ${ }^{2} 321$

\section{Study outcome variables}

The main outcome variables in the study were postneonatal mortality (death between 1 and 11 months), infant mortality (death between birth and 11 months), child mortality (death between 12 and 59 months) and total under-5 mortality (death between birth and 59 months). Each death case was coded as 1 , and each non-death (alive) case was coded as 0 .

\section{Study factors}

Study factors for this study were based on the Mosley and Chen framework of factors influencing child survival in developing countries; ${ }^{22}$ other previous studies ${ }^{23-29}$ on childhood mortality (particularly in the sub-Saharan Africa region) also played a role in the assessment of potential study variables. These variables were adapted to the data available in the merged data set and comprised geographic location of place of residence (categorised as urban-rural residence), a household measure of income and a range of individual-level factors.

Individual-level factors consisted of maternal characteristics (religion, education, literacy level, age, body mass index, occupation and desire for pregnancy); child characteristics (sex, birth place, size, mode of delivery, delivery assistance, and a combination of birth order and birth interval) and paternal education.

The only household-level factor used was the wealth index variable, which measured the economic status of the households interviewed in the survey. A principal components analysis was used in constructing the wealth index. ${ }^{30}$ Weights were assigned to the household facilities and assets of respondents. The facilities and assets included were those that were consistent across the pooled NDHS data: television, radio, refrigerator, car, bicycle, motorcycle, source of drinking water, type of toilet facility, electricity and type of building materials used in the place of dwelling. In the NDHS data set, the household wealth index was categorised into five quintiles: poorest, poorer, middle, richer and richest. However, in the analysis, the household wealth index was recategorised into three groups: the bottom $40 \%$ of households were referred to as poor households, the next $40 \%$ as middle households and the top $20 \%$ as rich households. 


\section{Statistical analysis}

First, an estimation of mortality rates for singleton live births in each of the measured age ranges was conducted according to the year of survey, using a method similar to that described by Rutstein and Rojas. ${ }^{31}$ This step was followed by a multivariable analysis that independently assessed the effect of each factor for each of the study outcome variables after adjusting for potential confounding variables; Cox proportional hazard regression models were used in this assessment.

The multivariable analysis model for each of the study outcomes performed used a stepwise backwards elimination process to identify independent variables that were significantly associated with the study outcomes. To reduce any statistical error in our analyses, we double checked our backward elimination method by using the following procedures: (1) we entered only potential risk factors with a $\mathrm{p}$ value $<0.20$ obtained in the univariable analysis for the backward elimination process, (2) we tested the backward elimination by including all of the variables (all potential confounding factors) and (3) we tested and reported any collinearity in the final model.

The HRs and their 95\% CIs obtained from the adjusted Cox proportional models were used to measure the effect of predictor variables with the study outcomes (infant, postneonatal, child and under-5 deaths). All statistical analyses were conducted using 'SVY' commands in STATA/MP V.12.0 (StataCorp, College Station, Texas, USA) to adjust for the cluster sampling survey design, weights and SEs.

\section{RESULTS}

A weighted total of 6285 deaths of children aged under 5 years occurred within the 5-year period preceding the survey interview dates: 1859 deaths between 1 and 11 months (postneonatal mortality); 4113 deaths occurred between birth and 11 months (infant mortality); and 2172 deaths between 12 and 59 months (child mortality). The distribution of 6285 children who died before their fifth birthday according to community-level, individual-level and household-level characteristics are presented in table 1 . In the pooled NDHS data, more than $74 \%$ of the postneonatal, infant, child and under-5 deaths occurred in the rural areas. Delivery assisted by non-health professionals had the highest per cent of deaths compared with those assisted by health professionals (56.4\% postneonatal, $51.2 \%$ infant, $65.6 \%$ child and $56.1 \%$ under-5).

Between 2003 and 2013, IMR for singleton live-born infants decreased by approximately $30 \%$, from 84 deaths per 1000 live births in 2003 to 59 deaths in 2013; PMR fell by approximately $40 \%$, from 43 to 26 deaths; CMR declined by $44 \%$, from 48 to 27 deaths; and U5MR dropped by $36 \%$, from 132 to 85 deaths (figure 1 ).

\section{Risk factors for postneonatal mortality (1-11 months)}

Postneonates born to younger mothers (age $<20$ years) reported a significantly higher risk of postneonatal deaths (HR=3.45, CI 2.19 to 5.46) compared with those born to mothers aged between 30 and 39 years. Postneonates living in rural areas were also more likely to die (HR=1.48, CI 1.16 to 1.89 ) than those living in urban areas. When place of residence was replaced by household wealth index in the final model, there was a significantly higher risk of postneonatal death for those born to mothers from poor households $(\mathrm{HR}=2.47$, CI 1.76 to 3.47 ) and middle-class households ( $\mathrm{HR}=1.93$, CI 1.40 to 2.67) as compared with wealthy households. Other factors that were significantly associated with postneonatal deaths included having a mother with no formal education ( $\mathrm{HR}=1.30$, CI 1.01 to 1.66); having a birth size that was perceived as small or smaller (HR=1.44, CI 1.14 to 1.81); and having a fourth or higher birth order with a short birth interval $\leq 2$ years (HR=1.92, CI 1.40 to 2.64; table 2).

\section{Risk factors for infant mortality (0-11 months)}

Infants born to mothers from poor households $(\mathrm{HR}=1.40$, CI 1.10 to 1.78$)$ and middle-class households $(\mathrm{HR}=1.37$, CI 1.11 to 1.69$)$ had a higher risk of infant mortality than those born in wealthy households. Infants whose birth size was perceived as small or smaller had a 1.74 times greater risk of dying than those perceived as average or larger in size. Male infants were also more likely to die (HR=1.23, CI 1.09 to 1.39 ) than female infants, as were infants living in rural areas $(\mathrm{HR}=1.23$, CI 1.03 to 1.47). Other significant factors that affected infant mortality included infants born to mothers $<20$ years old $(\mathrm{HR}=3.04$, CI 2.28 to 4.05$)$; infants of fourth or higher birth order with a birth interval $\leq 2$ years $(\mathrm{HR}=1.94$, CI 1.56 to 2.41); infants of illiterate mothers (HR=1.38, CI 1.11 to 1.84 ) and infants whose deliveries occurred by caesarean section $(\mathrm{HR}=1.74$, CI 1.24 to 2.45 ; table 2 ).

\section{Risk factors for child mortality (age 12-59 months)}

Children aged between 12 and 59 months had a significantly higher risk of child mortality if their mothers had either no formal education ( $\mathrm{HR}=2.13$, CI 1.56 to 2.89) or else had only a primary education ( $\mathrm{HR}=1.58$, CI 1.13 to 2.20). Similar findings were observed when we replaced maternal education with paternal education in the final model; children whose fathers had no formal education were more likely to die ( $\mathrm{HR}=1.73$, CI 1.34 to 2.22). Children from poor households were also more likely to die (HR=1.72, CI 1.19 to 2.49 ), as were children whose mothers resided in rural areas $(\mathrm{HR}=1.52$, CI 1.16 to 1.99 ; table 3 ).

\section{Risk factors for under-5 mortality (age 0-59 months)}

Multivariable analyses indicated significant associations with under-5 mortality in those of a fourth or higher birth order with a short birth interval $\leq 2$ years $(\mathrm{HR}=1.89$, CI 1.58 to 2.26); children of a second or third higher birth order with a short birth interval $\leq 2$ years were also more likely to die ( $\mathrm{HR}=1.49$, CI 1.20 to 1.85$)$. Additional 
Table 1 Distribution of postneonatal, infant, child and under-5 mortality, reported in three demographic and health surveys in Nigeria, 2003-2013 ( $\mathrm{N}=6285)$

\begin{tabular}{|c|c|c|c|c|}
\hline Variables & Postneonatal, n (\%) & Infant, $\mathbf{n}(\%)$ & Child, n (\%) & Under-5, n (\%) \\
\hline \multicolumn{5}{|l|}{ Community-level factors } \\
\hline \multicolumn{5}{|l|}{ Residence type } \\
\hline Urban & 444 (23.9) & $1042(25.3)$ & $379(17.4)$ & $1421(22.6)$ \\
\hline Rural & $1416(76.1)$ & $3071(74.7)$ & $1793(82.6)$ & $4864(77.4)$ \\
\hline \multicolumn{5}{|l|}{ Geopolitical zone } \\
\hline North Central & $250(13.5)$ & $521(12.7)$ & $211(9.7)$ & $732(11.6)$ \\
\hline North East & 377 (20.3) & $806(19.6)$ & $486(22.4)$ & $1291(20.5)$ \\
\hline North West & $721(38.8)$ & $1530(37.2)$ & $1052(48.5)$ & $2583(41.1)$ \\
\hline South East & $193(10.4)$ & $405(9.9)$ & $135(6.2)$ & $540(8.6)$ \\
\hline South West & $174(9.4)$ & $438(10.6)$ & $169(7.8)$ & $607(9.7)$ \\
\hline South South & $143(7.7)$ & $413(10.0)$ & $119(5.5)$ & $533(8.5)$ \\
\hline \multicolumn{5}{|l|}{ Household wealth index } \\
\hline Poor & $845(45.4)$ & $1784(43.4)$ & $1088(50.1)$ & $2872(45.7)$ \\
\hline Middle & $760(40.9)$ & 1658 (40.3) & $867(39.9)$ & 2525 (40.2) \\
\hline Rich & $254(13.7)$ & 671 (16.3) & $218(10.0)$ & $889(14.1)$ \\
\hline \multicolumn{5}{|l|}{ Individual-related factors } \\
\hline \multicolumn{5}{|l|}{ Mother's religion* } \\
\hline Traditionalist and other & $190(10.3)$ & $366(9.0)$ & $252(11.6)$ & $618(9.9)$ \\
\hline Islam & $1030(55.7)$ & $2226(54.4)$ & $1410(65.0)$ & $3636(58.1)$ \\
\hline Catholic and other Christian & $618(33.4)$ & $1472(36.0)$ & $495(22.8)$ & 1966 (31.4) \\
\hline \multicolumn{5}{|l|}{ Mother's age at birth } \\
\hline$<20$ & $125(6.7)$ & $322(7.8)$ & $91(4.2)$ & $413(6.6)$ \\
\hline $20-29$ & $886(47.7)$ & 1929 (46.9) & $1023(47.1)$ & $2952(47.0)$ \\
\hline $30-39$ & $641(34.5)$ & $1394(33.9)$ & $780(35.9)$ & $2174(34.6)$ \\
\hline $40-49$ & $206(11.1)$ & $468(11.4)$ & $278(12.8)$ & $746(11.9)$ \\
\hline \multicolumn{5}{|l|}{ Mother's education } \\
\hline No education & $1078(58.0)$ & $2213(53.8)$ & $1435(66.1)$ & $3648(58.0)$ \\
\hline Primary & $382(20.5)$ & 917 (22.3) & $432(19.9)$ & $1350(21.5)$ \\
\hline Secondary or higher & 399 (21.5) & 983 (23.9) & $305(14.0)$ & $1287(20.5)$ \\
\hline \multicolumn{5}{|l|}{ Mother's literacy level ${ }^{*}$} \\
\hline Cannot read at all & $1312(70.6)$ & $2755(67.0)$ & 1691 (77.9) & $4446(70.7)$ \\
\hline Able to read & $542(29.1)$ & 1330 (32.3) & $465(21.4)$ & 1795 (28.6) \\
\hline \multicolumn{5}{|l|}{ Mother's desire for pregnancy* } \\
\hline Wanted then & $1611(86.6)$ & 3541 (86.1) & 1909 (87.9) & $5450(86.7)$ \\
\hline Wanted later & $112(6.1)$ & $234(5.7)$ & $107(4.9)$ & $341(5.4)$ \\
\hline Wanted no more & $53(2.9)$ & $124(3.02)$ & $48(2.2)$ & $172(2.7)$ \\
\hline \multicolumn{5}{|l|}{ Mother's body mass index* } \\
\hline Greater than 18.5 & $1621(87.2)$ & 3634 (88.3) & $1892(87.1)$ & $5526(87.9)$ \\
\hline Less than or equal to 18.5 & $201(10.8)$ & 408 (9.9) & $241(11.1)$ & $650(10.3)$ \\
\hline \multicolumn{5}{|l|}{ Mother's working status* } \\
\hline Not working & $632(35.2)$ & $1402(35.4)$ & $784(37.2)$ & $2186(36.0)$ \\
\hline Working & $1158(64.5)$ & 2548 (64.3) & $1320(62.6)$ & $3867(63.7)$ \\
\hline \multicolumn{5}{|l|}{ Father's education* } \\
\hline No education & $865(46.5)$ & $1762(42.8)$ & $1151(53.0)$ & $2913(46.4)$ \\
\hline Primary & 388 (20.9) & $867(21.1)$ & $450(20.7)$ & $1316(20.9)$ \\
\hline Secondary or higher & $552(29.7)$ & $1360(33.1)$ & $509(23.5)$ & $1869(29.7)$ \\
\hline \multicolumn{5}{|l|}{ Sex of child } \\
\hline Female & $887(47.7)$ & $1838(44.7)$ & $1057(48.7)$ & $2895(46.1)$ \\
\hline Male & 973 (52.3) & 2275 (55.3) & 1115 (51.3) & $3390(53.9)$ \\
\hline \multicolumn{5}{|l|}{ Mother's perceived baby size* } \\
\hline Small or very small & $301(16.2)$ & 795 (19.3) & $352(16.2)$ & $1148(18.3)$ \\
\hline Average or larger & $1446(77.8)$ & 3006 (73.1) & $1702(78.4)$ & 4708 (74.9) \\
\hline \multicolumn{5}{|l|}{ Birth order and birth interval } \\
\hline First child & $347(18.7)$ & $947(23.0)$ & $370(17.0)$ & $1317(21)$ \\
\hline 2 or 3 child, interval $>2$ & $337(18.1)$ & 699 (17.0) & 398 (18.3) & $1098(17.5)$ \\
\hline 2 or 3 child, interval $\leq 2$ & $229(12.3)$ & $497(12.1)$ & $218(10.0)$ & $715(11.4)$ \\
\hline
\end{tabular}




\begin{tabular}{|c|c|c|c|c|}
\hline 4 or more child, interval >2 & $542(29.1)$ & $1114(27.1)$ & $700(32.2)$ & $1814(28.9)$ \\
\hline \multicolumn{5}{|l|}{ Mode of delivery ${ }^{*}$} \\
\hline Non-caesarean & $1831(98.5)$ & 3978 (96.7) & 2149 (98.9) & $6127(97.5)$ \\
\hline Caesarean section & $17(0.9)$ & $103(2.5)$ & $13(0.6)$ & $115(1.8)$ \\
\hline Health professional & $493(26.5)$ & 1307 (31.8) & 411 (18.9) & $1718(27.3)$ \\
\hline Non-Health professional & 1049 (56.4) & $2104(51.2)$ & $1424(65.6)$ & $3528(56.1)$ \\
\hline \multicolumn{5}{|l|}{ Birth place of child* } \\
\hline Health facility & $271(25.3)$ & $1239(30.1)$ & $386(17.8)$ & 1625 (25.9) \\
\hline Home & 1307 (70.3) & $2673(65.0)$ & $1693(78.0)$ & $4367(69.5)$ \\
\hline
\end{tabular}

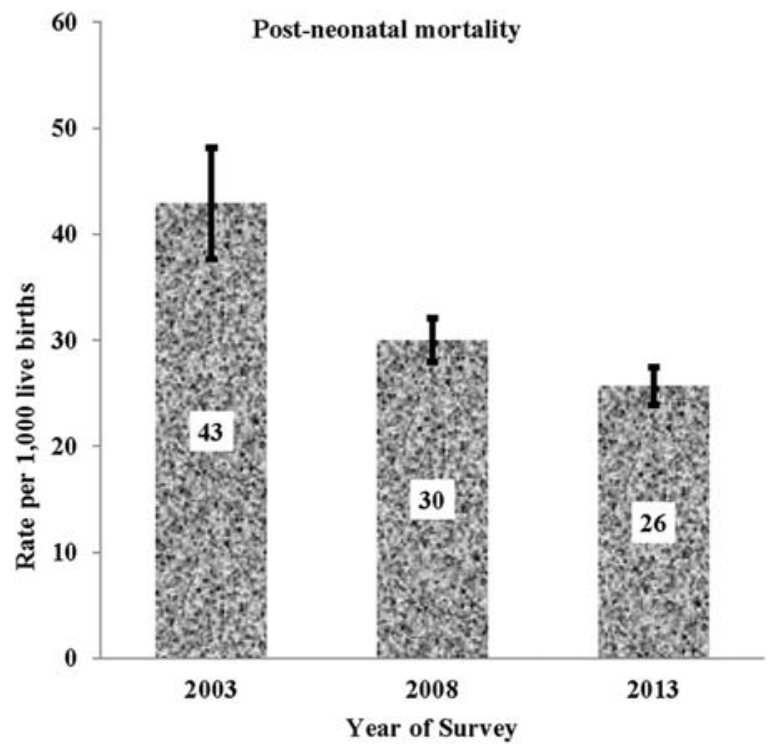

Infant mortality

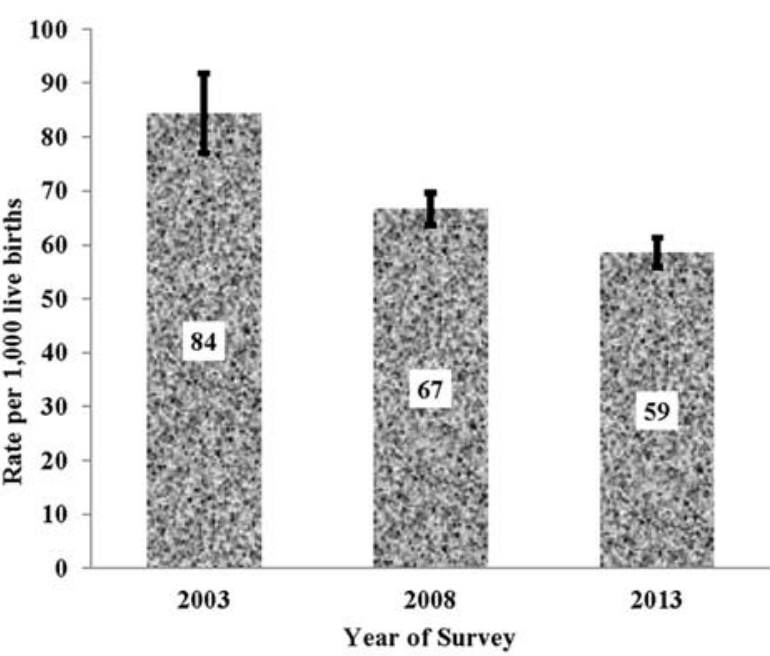

Child mortality
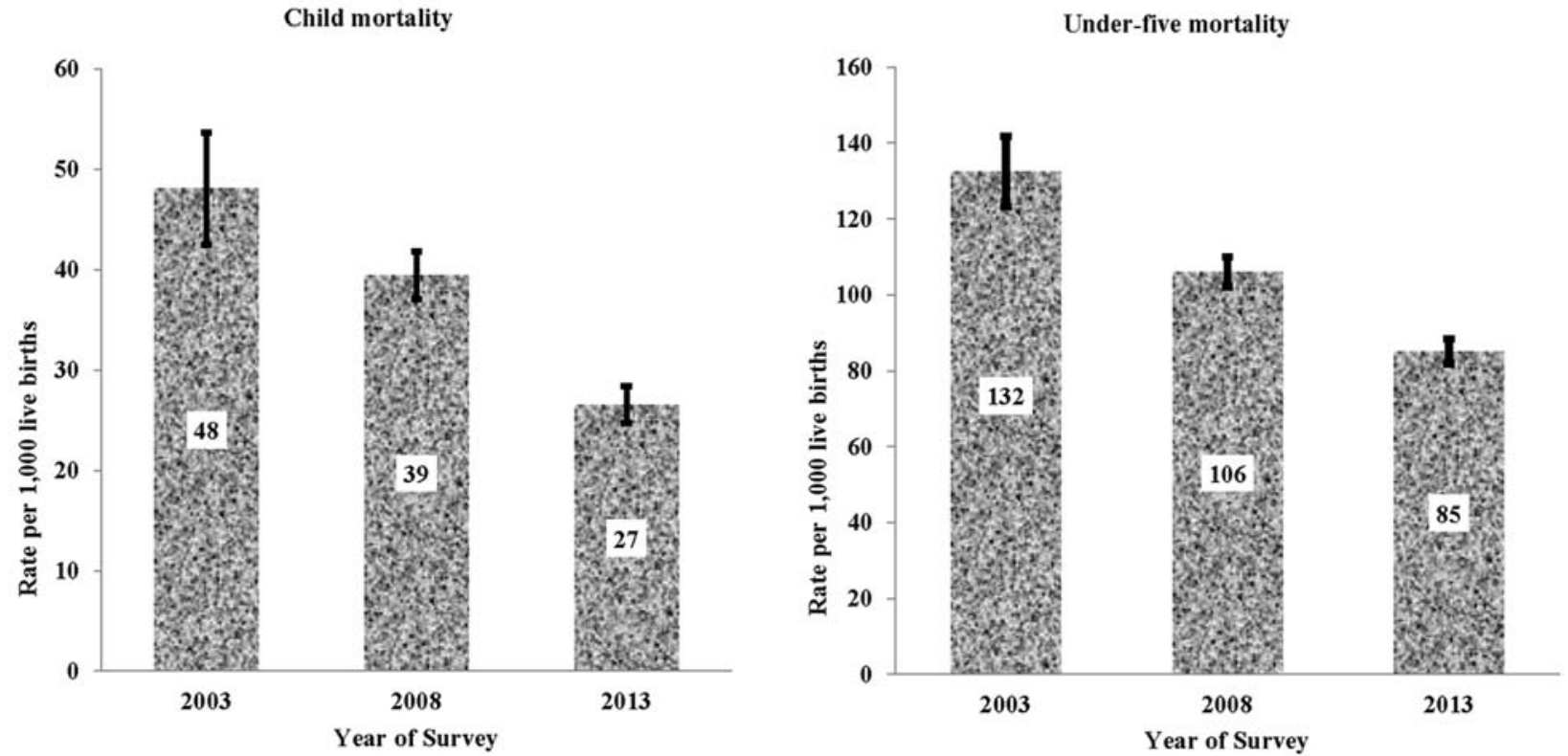

Figure 1 Postneonatal, infant, child and under-5 deaths per 1000 live births (singleton), with $95 \% \mathrm{Cl}$ by year of Nigeria Demographic and Health Surveys (NDHS), 2003-2013. 
Table 2 Adjusted $\mathrm{HR}(95 \% \mathrm{Cl})$ for variables significantly associated with postneonatal and infant mortality

\begin{tabular}{|c|c|c|c|c|c|c|}
\hline \multirow[b]{2}{*}{ Variables } & \multicolumn{3}{|c|}{ Postneonatal (1-11 months) } & \multicolumn{3}{|c|}{ Infant (0-11 months) } \\
\hline & $\overline{H^{*}}{ }^{*} \dagger$ & $(95 \% \mathrm{Cl})$ & p Value & $\mathbf{H R}^{*} \boldsymbol{\dagger}$ & $(95 \% \mathrm{Cl})$ & p Value \\
\hline \multicolumn{7}{|l|}{ Year of survey } \\
\hline 2003 & 1.00 & & & 1.00 & & \\
\hline 2008 & 0.70 & (0.53 to 0.93 ) & 0.014 & 0.80 & (0.64 to 0.99$)$ & 0.038 \\
\hline 2013 & 0.52 & (0.38 to 0.71$)$ & $<0.001$ & 0.66 & (0.53 to 0.83 ) & $<0.001$ \\
\hline \multicolumn{7}{|l|}{ Residence type } \\
\hline Urban & 1.00 & & & 1.00 & & \\
\hline Rural & 1.48 & (1.16 to 1.89$)$ & 0.002 & 1.23 & (1.03 to 1.47$)$ & 0.023 \\
\hline \multicolumn{7}{|l|}{ Household wealth index } \\
\hline Rich & & & & 1.00 & & \\
\hline Middle & - & - & - & 1.37 & (1.11 to 1.69 ) & 0.003 \\
\hline Poor & - & - & - & 1.40 & (1.10 to 1.78$)$ & 0.006 \\
\hline \multicolumn{7}{|l|}{ Individual-level factors } \\
\hline \multicolumn{7}{|l|}{ Mother's education } \\
\hline Secondary or higher & 1.00 & & & 1.00 & & \\
\hline Primary & 1.13 & (0.86 to 1.48$)$ & 0.388 & 1.01 & (0.95 to 1.39$)$ & 0.418 \\
\hline No education & 1.30 & (1.01 to 1.66$)$ & 0.044 & 1.38 & (1.11 to 1.84 ) & 0.039 \\
\hline \multicolumn{7}{|l|}{ Mother's age (years) } \\
\hline $30-39$ & 1.00 & & & 1.00 & & \\
\hline Less than 20 & 3.45 & (2.19 to 5.46$)$ & $<0.001$ & 3.04 & (2.28 to 4.05 ) & $<0.001$ \\
\hline $20-29$ & 1.59 & (1.23 to 2.04$)$ & $<0.001$ & 1.31 & (1.12 to 1.54$)$ & 0.001 \\
\hline $40-49$ & 1.08 & (0.82 to 1.42$)$ & 0.578 & 1.09 & (0.90 to 1.31$)$ & 0.385 \\
\hline \multicolumn{7}{|l|}{ Mother's perceived baby size } \\
\hline Average or large & 1.00 & & & 1.00 & & \\
\hline Small or very small & 1.44 & (1.14 to 1.81$)$ & 0.002 & 1.74 & (1.50 to 2.02$)$ & $<0.001$ \\
\hline \multicolumn{7}{|l|}{ Birth order and birth interval } \\
\hline 2nd or 3 rd child, interval $>2$ years & 1.00 & & & & & \\
\hline 1st child & 1.13 & $(0.80$ to 1.61$)$ & 0.488 & 1.38 & (1.10 to 1.72$)$ & 0.005 \\
\hline 2 nd or $3 r d$ child, interval $\leq 2$ years & 1.64 & (1.13 to 2.37$)$ & 0.009 & 1.52 & (1.18 to 1.97$)$ & 0.001 \\
\hline 4th or higher child, interval $>2$ years & 1.39 & (1.05 to 1.85$)$ & 0.024 & 1.30 & (1.06 to 1.60$)$ & 0.014 \\
\hline 4 th or higher child, interval $\leq 2$ years & 1.92 & (1.40 to 2.64$)$ & $<0.001$ & 1.94 & (1.56 to 2.41$)$ & $<0.001$ \\
\hline \multicolumn{7}{|l|}{ Sex of child } \\
\hline Female & - & - & - & 1.00 & & \\
\hline Male & - & - & - & 1.23 & (1.09 to 1.39 ) & 0.001 \\
\hline \multicolumn{7}{|l|}{ Mode of delivery } \\
\hline Non-caesarean & - & - & - & 1.00 & & \\
\hline Caesarean section $\ddagger$ & - & - & - & 1.74 & (1.24 to 2.45$)$ & $<0.001$ \\
\hline
\end{tabular}

*Independent variables adjusted for: place of residence, wealth index, mother's (religion, education, age, body mass index, work status and desire for pregnancy), father's education, child's (sex, birth place, body size, mode of delivery, delivery assistance, birth order and birth interval).

†Multiple births were excluded from the analysis; $p$ values based on Cox regression.

$\ddagger$ Caesarean section is a combination of both elective and emergency caesarean—variables that were not statistically significant.

associations included having a mother aged $<20$ years $(\mathrm{HR}=1.47$, CI 1.27 to 1.71$)$ and having a mother with no formal education (HR=1.19, CI 1.02 to 1.41 ). Children from poor households were about one and a half times as likely to die within 59 months of life as compared with those from rich households (HR=1.43, CI 1.17 to 1.76). Other significant factors that influenced a child's under-5 mortality included having a birth size that was perceived by the mother to be smaller than the average size ( $\mathrm{HR}=1.47$, CI 1.29 to 1.68$)$; being of male gender (HR=1.24, CI 1.12 to 1.38 ); having had a caesarean section delivery (HR=1.74, CI 1.25 to 2.42$)$ and mother residing in a rural rather than an urban area $(\mathrm{HR}=1.29$, CI 1.11 to 1.50 ) (table 3 ).

\section{DISCUSSION}

We found that over the past 10 years, there has been a steady decline in the rates of infant, postneonatal, child and under-5 mortalities in Nigeria. While this trend shows that Nigeria is making progress, the pace of this progress still remains too slow to achieve the Millennium Development Goal of reducing Nigeria's child mortality to 76 deaths per 1000 live births by the year 2015 .

The findings from this present study show that child mortality risk factors were consistent across each of the four age ranges and related to living in a poor household, living in a rural area and having a mother with no schooling. Infant, postneonatal and under-5 deaths were also associated with having a younger mother ( $<20$ years), 
Table 3 Adjusted HR $(95 \% \mathrm{Cl})$ for variables significantly associated with child and under-5 mortality

\begin{tabular}{|c|c|c|c|c|c|c|}
\hline \multirow[b]{2}{*}{ Variables } & \multicolumn{3}{|c|}{ Child (12-59 months) } & \multicolumn{3}{|c|}{ Under-5 (0-59 months) } \\
\hline & $\mathbf{H R}^{\star} \boldsymbol{\dagger}$ & $(95 \% \mathrm{Cl})$ & p Value & $\mathrm{HR}^{\star} \boldsymbol{\dagger}$ & $(95 \% \mathrm{Cl})$ & p Value \\
\hline \multicolumn{7}{|l|}{ Year of survey } \\
\hline 2003 & 1.00 & & & 1.00 & & \\
\hline 2008 & 0.71 & (0.54 to 0.93$)$ & 0.015 & 0.75 & $(0.63$ to 0.90$)$ & 0.002 \\
\hline 2013 & 0.50 & (0.38 to 0.68$)$ & $<0.001$ & 0.63 & (0.52 to 0.76$)$ & $<0.001$ \\
\hline \multicolumn{7}{|l|}{ Residence type } \\
\hline Urban & 1.00 & & & 1.00 & & \\
\hline Rural & 1.52 & (1.16 to 1.99$)$ & 0.002 & 1.29 & (1.11 to 1.50$)$ & 0.001 \\
\hline \multicolumn{7}{|l|}{ Household wealth index } \\
\hline Rich & 1.00 & & & 1.00 & & \\
\hline Middle & 1.63 & (1.14 to 2.32$)$ & 0.007 & 1.42 & (1.18 to 1.70$)$ & 0.001 \\
\hline Poor & 1.72 & (1.19 to 2.49$)$ & 0.004 & 1.43 & (1.17 to 1.76$)$ & 0.001 \\
\hline \multicolumn{7}{|l|}{ Individual-level factors } \\
\hline \multicolumn{7}{|l|}{ Mother's education } \\
\hline Secondary or higher & 1.00 & & & 1.00 & & \\
\hline Primary & 1.58 & (1.13 to 2.20$)$ & 0.007 & 1.11 & (0.93 to 1.32$)$ & 0.244 \\
\hline No education & 2.13 & (1.56 to 2.89 ) & $<0.001$ & 1.19 & (1.02 to 1.41$)$ & 0.032 \\
\hline \multicolumn{7}{|l|}{ Mother's age (years) } \\
\hline 30-39 & & & & 1.00 & & \\
\hline Less than 20 & - & - & - & 1.44 & (1.13 to 1.85$)$ & 0.004 \\
\hline $20-29$ & - & - & - & 1.04 & (0.92 to 1.19$)$ & 0.519 \\
\hline $40-49$ & - & - & - & 1.47 & (1.27 to 1.71$)$ & $<0.001$ \\
\hline \multicolumn{7}{|l|}{ Mother's perceived baby size } \\
\hline Average or large & & & & 1.00 & & \\
\hline Small or very small & - & - & - & 1.47 & (1.29 to 1.68$)$ & $<0.001$ \\
\hline \multicolumn{7}{|l|}{ Birth order and birth interval } \\
\hline \multicolumn{7}{|l|}{ 2nd or 3rd child, interval $>2$ years } \\
\hline 1st child & - & - & - & 1.42 & (1.17 to 1.71$)$ & $<0.001$ \\
\hline 2nd or 3rd child, interval $\leq 2$ years & - & - & - & 1.48 & (1.19 to 1.84$)$ & $<0.001$ \\
\hline 4 th or higher child, interval $>2$ years & - & - & - & 1.10 & (0.93 to 1.30$)$ & 0.288 \\
\hline 4 th or higher child, interval $\leq 2$ years & - & - & - & 1.89 & (1.58 to 2.26$)$ & $<0.001$ \\
\hline \multicolumn{7}{|l|}{ Sex of child } \\
\hline Female & - & - & - & 1.00 & & \\
\hline Male & - & - & - & 1.24 & (1.12 to 1.38$)$ & $<0.001$ \\
\hline \multicolumn{7}{|l|}{ Mode of delivery } \\
\hline Non-caesarean & - & - & - & 1.00 & & \\
\hline Caesarean section $\ddagger$ & - & - & - & 1.74 & (1.25 to 2.42$)$ & 0.001 \\
\hline
\end{tabular}

*Independent variables adjusted for: place of residence, wealth index, mother's (religion, education, age, body mass index, work status and desire for pregnancy), father's education, child's (sex, birth place, body size, mode of delivery, delivery assistance, birth order and birth interval).

†Multiple births were excluded from the analysis; $p$ values based on Cox regression.

$\ddagger$ Caesarean section is a combination of both elective and emergency caesarean—variables that were not statistically significant.

being perceived as a small or very small newborn by their mothers, and having a higher birth order with a birth interval $\leq 2$ years. Previous delivery by caesarean section and being of the male gender were significantly associated with infant and under- 5 child mortality.

Our study's findings of greater mortality risk for children of all four age ranges living in poor households are similar to those reported in earlier reviews. Economic status has been reported as having a great impact on children, particularly those in the postneonatal stage. ${ }^{32-34}$ In Nigeria, more than two-thirds of the population live below the international poverty line of $\$ 1.25$ per day. ${ }^{35}$ Such poverty limits the opportunities for most mothers to access appropriate healthcare services for their children, resulting in a high probability of infant and child deaths.
Past studies have also shown that there are high risks of mortality among children aged less than 5 years whose mothers had no schooling. ${ }^{33}$ 36-38 Our study also found that children of mothers with no schooling are at a greater risk of death across all four age groups compared with those whose mothers had a secondary or higher level of education. Educated mothers are more likely to have better knowledge about child health and modern healthcare services; thus, the mother's education is a key determinant of poor child health. ${ }^{39}$ Improved maternal healthcare-seeking behaviours, ${ }^{40}{ }^{41}$ such as immunisation and feeding practices, may in turn positively influence child survival. Educated mothers are additionally more likely to reside in socially and economically developed areas that have 
well-equipped medical facilities, and good water and sanitation infrastructure. ${ }^{42}$

The current study found that children aged under 5 years born to mothers living in rural areas had a higher mortality risk compared with those living in urban areas. This finding is consistent with mortality study conducted in Bangladesh, ${ }^{36}$ Burkina Faso ${ }^{43}$ and Rwanda. ${ }^{44}$ The significantly higher risk of death among children who live in rural areas in Nigeria, noted in the present study, may be attributed to limited access to healthcare facilities, poor educational and transport services, unavailability of a safe water supply and inadequate basic sanitation facilities. Such conditions disproportionally hinder rural dwellers from receiving adequate healthcare and social and economic services, which adversely affects child survival. ${ }^{45}$

Children born to mothers younger than 20 years of age were at a greater risk of infant, postneonatal and under-5 mortality. Factors contributing to this finding could include physical immaturity, pregnancy complications, poor nutritional status, inadequate use of maternal health services and inexperience in child rearing among younger mothers. ${ }^{46}$

The risks of infant and under-5 mortalities were significantly higher for male children than for female children; postneonatal and child mortalities did not significant differ by gender in the multivariable analyses. Biological factors ${ }^{47-49}$ may be possible explanations to the increased risk of male deaths. The high rate of infant and under-5 deaths among male children may be due to late development of fetal lung maturity in the first week of life, ${ }^{50}$ resulting in a higher incidence of respiratory diseases in male children compared with female children.

Findings from this study indicate that children of fourth or higher birth order born with shorter birth intervals ( $\leq 2$ years) were at a greater risk of dying at infant, postneonatal and under-5 ages. This result is consistent with previous studies conducted in India and Kenya, ${ }^{51-53}$ and may reflect that short-interval births may adversely affect maternal health and well-being, and cause economic resource competition among infants, particularly in poorer households. ${ }^{51}$ We also found that the risk of infant, postneonatal and under-5 mortality was significantly higher for children whose mother perceived their size to be small or very small after birth compared with those who were perceived as average or larger size. This observation may be explained by the influence of biologically associated risk factors such as low birth weight, poor nutritional status and prematurity birth. ${ }^{5455}$

A higher likelihood of infant and under-5 deaths was associated with mothers who delivered by caesarean section compared with vaginal deliveries. This finding is not in agreement with study conducted in Sao Paulo, Brazil, which indicated a statistically insignificant relationship between caesarean delivery and infant mortality. ${ }^{56}$ Additionally, a cross-sectional study conducted in India in 2012 also reported an insignificant relationship between under-5 mortality and caesarean delivery. ${ }^{23}$ The possible explanation for the high risk associated with caesarean section in our current study may be attributed to negative perceptions, such as misconception, fear and aversion to caesarean section, among mothers in Nigeria. ${ }^{57} 58$ This could explain why pregnant mothers are presented to health facilities after experiencing labour, at home or elsewhere, with life-threatening complications for emergency caesarean section. ${ }^{59}$

\section{Limitations}

Some limitations that need to be considered when interpreting the results of this study include: (A) the crosssectional design limits any conclusions about causality of the factors we have examined; (B) the antecedent health and nutritional status history of children under 5 years old, especially for those children who had died, and causes of death were lacking in the NDHS surveys, and $(\mathrm{C})$ this study did not adjust for effect of small-scale geographical inequality as demonstrated by previous studies. ${ }^{44} 60$ However, this study adjusted for intracluster correlation which is an appropriate statistical method for examining mortality from complex cluster sample survey data. ${ }^{61}$

\section{CONCLUSION}

This study found that under-5 mortality has declined significantly by $37 \%$ over a 10 -year period after adjusting for individual-level, household-level and community-level factors. Our findings indicated that living in poor households, living in rural areas and having mothers with no schooling are common significant risk factors for mortality across all four age ranges (infant, postneonatal, child and under-5) in Nigeria. Community-based interventions that target mothers living in rural areas and mothers with low socioeconomic status are needed for improving child survival in Nigeria.

Contributors OKE and KEA were involved in the conception and design of this study. OKE conducted the literature review, carried out the analysis and drafted the manuscript. KEA, MJD, JJH and ANP provided advice on interpretation, and revised and edited the manuscript. All authors read and approved the manuscript.

Funding This research received no specific grant from any funding agency in the public, commercial or not-for-profit sectors.

Competing interests None.

Ethics approval This study was based on an analysis of existing public domain survey data sets that is freely available online with all identifier information removed. The first author communicated with MEASURE DHS/ICF International, and permission was granted to download and use the data for his doctoral dissertation by the School of Medicine at the University of Western Sydney, Australia.

Provenance and peer review Not commissioned; externally peer reviewed.

Data sharing statement No additional data are available.

Open Access This is an Open Access article distributed in accordance with the Creative Commons Attribution Non Commercial (CC BY-NC 4.0) license, which permits others to distribute, remix, adapt, build upon this work noncommercially, and license their derivative works on different terms, provided the original work is properly cited and the use is non-commercial. See: http:// creativecommons.org/licenses/by-nc/4.0/ 


\section{REFERENCES}

1. UNICEF/WHO. Levels and trends in child mortality. Report 2013. http://www.who.int/maternal_child_adolescent/documents/levels_ trends_child_mortality_2013.pdf?ua=1 (accessed Jan 2014).

2. National Population Commission. Federal Republic of Nigeria: final report on Nigeria Demographic and Health Survey 2003. Calverton, MD, USA: ORC Macro.

3. National Population Commission. Federal Republic of Nigeria: final report on Nigeria Demographic and Health Survey 2013. Calverton, MD, USA: ORC Macro.

4. Ogunlade $\mathrm{S}$, Mezue $\mathrm{C}$, Kibet $\mathrm{M}$, et al. Infant and child mortality in Nigeria. AHFAD J 1987;4:205-26.

5. Adetunji JA. Infant mortality in Nigeria: effects of place of birth, mother's education and region of residence. J Biosoc Sci 1994;26:469-77.

6. Lawoyin T. Risk factors for infant mortality in a rural community in Nigeria. J R Soc Promot Health 2001;121:114-18.

7. Ogunjuyigbe PO. Under-five mortality in Nigeria: perception and attitudes of the Yorubas towards the existence of "Abiku". Demogr Res 2004;11:43-56.

8. Oni GA. Child mortality in Nigeria city: its levels and socio-economic differential. Soc Sci Med 1988;27:607-14.

9. Antai D, Ghilagaber G, Wedrén S, et al. Inequities in under-five mortality in Nigeria: differentials by religious affiliation of the mother. J Relig Health 2009;48:290-304.

10. Kayode G, Adekanmbi V, Uthman O. Risk factors and a predictive model for under-five mortality in Nigeria: evidence from Nigeria demographic and health survey. BMC Pregnancy Childbirth 2012;12:10.

11. Hong R. Effect of multiple birth on infant mortality in Bangladesh. J Paediatr Child Health 2006;42:630-5.

12. Uthman OA, Uthman MB, Yahaya I. A population-based study of effect of multiple birth on infant mortality in Nigeria. BMC Pregnancy Childbirth 2008;8:41

13. Olusanya BO. Perinatal outcomes of multiple births in southwest Nigeria. J Health Popul Nutr 2011;29:639-47.

14. Justesen A, Kunst $A$. Postneonatal and child mortality among twins in Southern and Eastern Africa. Int J Epidemiol 2000;29:678-83.

15. Katz J, West KP, Khatry SK, et al. Twinning rates and survival of twins in rural Nepal. Int $J$ Epidemiol 2001;30:802-7.

16. Alam N, Van Ginneken JK, Bosch AM. Infant mortality among twins and triplets in rural Bangladesh in 1975-2002. Trop Med Int Health 2007;12:1506-14.

17. Imaizumi Y. Infant mortality rates in single, twin and triplet births, and influencing factors in Japan, 1995-98. Paediatr Perinat Epidemiol 2001;15:346-51.

18. Kleinman JC, Fowler MG, Kessel SS. Comparison of infant mortality among twins and singletons: United States 1960 and 1983. Am J Epidemiol 1991;133:133-43.

19. Welcome MO. The Nigerian health care system: need for integrating adequate medical intelligence and surveillance systems. J Pharm Bioallied Sci 2011;3:470-8.

20. Titaley CR, Dibley MJ, Roberts CL. Type of delivery attendant, place of delivery and risk of early neonatal mortality: analyses of the 1994-2007 Indonesia Demographic and Health Surveys. Health Policy Plan 2011;27:405-16.

21. National Population Commission. Federal Republic of Nigeria: final report on Nigeria Demographic and Health Survey 2008. Calverton, MD, USA: ORC Macro.

22. Mosley WH, Chen LC. An analytical framework for the study of child survival in developing countries. Popul Dev Rev 1984;10:25-45.

23. Omariba DWR, Beaujot R, Rajulton F. Determinants of infant and child mortality in Kenya: an analysis controlling for frailty effects. Popul Res Policy Rev 2007;26:299-321.

24. Madise NJ, Banda EM, Benaya KW. Infant mortality in Zambia: socioeconomic and demographic correlates. Biodemogr Soc Biol 2003;50:148-66.

25. Kalipeni E. Determinants of infant mortality in Malawi: a spatial perspective. Soc Sci Med 1993;37:183-98.

26. Manda SOM. Birth intervals, breastfeeding and determinants of childhood mortality in Malawi. Soc Sci Med 1999;48:301-12.

27. Fotso JC, Cleland J, Mberu B, et al. Birth spacing and child mortality: an analysis of prospective data from the Nairobi urban health and demographic surveillance system. J Biosoc Sci 2013;45:779-98.

28. Vella V, Tomkins A, Nidku J, et al. Determinants of child mortality in South-West Uganda. J Biosoc Sci 1992;24:103-12.

29. Bailey M. Factors affecting infant and child mortality in Rural Sierra Leone. J Trop Pediatr 1988;34:165-8.

30. Deon F, Pritchett LH. Estimating wealth effects without expenditure data-or tears: an application to educational enrollments in states of India. Demography 2001;38:115-32.
31. Rutstein S, Rojas G. Guide to Demographic and Health Survey (DHS). Calverton, MD: ORC Macro, 2006.

32. Quamrul HC, Islam R, Hossain K. Effects of demographic characteristics on neonatal, post neonatal, infant and child mortality. J Biol Sci 2010;2:132-8.

33. Agha S. The determinants of infant mortality in Pakistan. Soc Sci Med 2000;51:199-208.

34. Arshad MM. Determinants of neonatal and post-neonatal mortality in Pakistan. Health Issues, Pakistan Development Review, 2002.

35. World Bank. World Development Indicators: Poverty rates at international poverty lines. http://wdi.worldbank.org/table/2.8 (accessed 12 Jun 2014).

36. Mondal N, Hossain K, Ali K. Factors influencing infant and child mortality: case study of Rajshahi District, Bangladesh. J Hum Ecol 2009;26:31-9.

37. Buor D. Mothers' education and childhood mortality in Ghana. Health Policy 2003;64:297-309.

38. Das Gupta M. Death clustering, mothers' education and the determinants of child mortality in rural Punjab, India. Popul Stud 1990;44:489-505

39. Caldwell JC. Education as a factor in mortality decline an examination of Nigerian data. Popul Stud 1979;33:395-413.

40. Basu AM, Stephenson R. Low levels of maternal education and the proximate determinants of childhood mortality: a little learning is not a dangerous thing. Soc Sci Med 2005;60:2011-23.

41. Mellington N, Cameron L. Female education and child mortality in Indonesia. Bull Indones Econ Stud 1999;35:115-44.

42. Palloni A. Mortality in Latin America: emerging patterns. Popul Dev Rev 1981;7:623-49.

43. Becher $\mathrm{H}$, Muller $\mathrm{O}$, Jahn $\mathrm{A}$, et al. Risk factors of infant and child mortality in rural Burkina Faso. Bull World Health Organ 2004;82:265-73.

44. Kazembe L, Clarke A, Kandala N-B. Childhood mortality in sub-Saharan Africa: cross-sectional insight into small-scale geographical inequalities from Census data. BMJ Open 2012;2:1-12.

45. Ezeh OK, Agho KE, Dibley MJ, et al. Determinants of neonatal mortality in Nigeria: evidence from the 2008 demographic and health survey. BMC Public Health 2014;14:521

46. Kamal SMM. What is the association between maternal age and neonatal mortality? An analysis of the 2007 Bangladesh Demographic and Health Survey. Asia Pac J Public Health 2011;XX:1-12.

47. Alonso V, Fuster V, Luna F. Causes of neonatal mortality in Spain (1975-98): influence of sex, rural-urban residence and age at death. J Biosoc Sci 2006;38:537-51.

48. DaVanzo J, Butz WP, Habicht JP. How biological and behavioural influences on mortality in Malaysia vary during the first year of life. Popul Stud 1983;37:381-402.

49. Bhuiya A, Streatfield K. Mothers' education and survival of female children in a rural area of Bangladesh. Popul Stud 1991;45:253-64.

50. Khoury MJ, Marks JS, McCarthy BJ, et al. Factors affecting the sex differential in neonatal mortality: the role of respiratory distress syndrome. Am J Obstet Gynecol 1985;151:777-82.

51. Rutstein SO. Effects of preceding birth intervals on neonatal, infant and under-five years mortality and nutritional status in developing countries: evidence from the demographic and health surveys. Int $J$ Gynecol Obstet 2005;89(Suppl 1):S7-24.

52. Whitworth A, Stephenson R. Birth spacing, sibling rivalry and child mortality in India. Soc Sci Med 2002;55:2107-19.

53. Mustafa HE, Odimegwu C. Socioeconomic determinants of infant mortality in Kenya: analysis of Kenya DHS 2003. Humanit Soc Sci 2008;2:1-16.

54. Lau C, Ambalavanan $\mathrm{N}$, Chakraborty $\mathrm{H}$, et al. Extremely low birth weight and infant mortality rates in the United States. Pediatrics 2013;131:855-60.

55. Alexander GR, Kogan M, Bader D, et al. US birth weight/gestational age-specific neonatal mortality: 1995-1997 rates for whites, Hispanics, and blacks. Pediatrics 2003;111:e61-6.

56. Machado CJ, Hill K. Determinants of neonatal and post-neonatal mortality in the City of São Paulo. Rev Bras Epidemiol 2003;6:345-58

57. Orji EO, Ogunniyi SO, Onwudiegwu U. Beliefs and perceptions of pregnant women at llesa about caesarean section. Trop J Obstet Gynaecol 2003;20:141-3.

58. Okonufua F. Optimizing caesarean section rates in West Africa. Lancet 2001;58:1289.

59. Sunday-Adeoye I, Kalu CA. Pregnant Nigerian women's view of cesarean section. Niger J Clin Pract 2011;14:276-9.

60. Adebayo SB, Fahrmeir L. Analysing child mortality in Nigeria with geoadditive discrete-time survival models. Stat Med 2005;24:709-28.

61. Park I, Lee H. Design effects for the weighted mean and total estimators under complex sampling. Surv Methodol 2004;30:183-93. 